\title{
COEFICIENTE DE DIGESTIBILIDADE APARENTE DE CINCO FONTES ENERGÉTICAS PARA O JACARÉ-DO-PANTANAL (Caiman yacare, Daudin, 1802) ${ }^{1}$
}

\begin{abstract}
RESUMO - Foi conduzido um ensaio de digestibilidade nas instalações da Cooperativa de Criadores de Jacaré-do-pantanal, na cidade de Cáceres-MT, com o objetivo de avaliar o valor nutricional de cinco alimentos para o jacaré-do-pantanal (Caiman yacare). Utilizouse um delineamento inteiramente casualizado, com 5 tratamentos e 3 repetições, sendo a unidade experimental formada por 3 jacarés, com peso total médio de $3940 \pm 240 \mathrm{~g}$, temperatura ambiente média de $30,5 \pm 5,0^{\circ} \mathrm{C}$ e temperatura média da água de $27,8 \pm$ $1,0^{\circ} \mathrm{C}$. A quantidade de alimento fornecida por repe-
\end{abstract}

\author{
FERNANDO RODRIGUES MACIEL ${ }^{2}$ \\ PRISCILA VIEIRA ROSA LOGATO ${ }^{3}$ \\ ELIAS TADEU FIALHO ${ }^{3}$ \\ RILKE TADEU FONSECA DE FREITAS ${ }^{3}$ \\ VICTOR MANUEL ALEIXO ${ }^{2}$
}

tição a cada dois dias foi padronizada em $20 \mathrm{~g}$ de matéria seca por unidade de peso metabólico $\left(\mathrm{kg}^{0,75}\right)$. As médias dos coeficientes de digestibilidade aparente foram comparadas pelo teste de Tukey. $\mathrm{O}$ coeficiente de digestibilidade aparente da matéria seca foi de 80,$78 ; 68,08 ; 69,91 ; 30,12$ e 58,95; e o coeficiente de digestibilidade aparente da energia bruta de 82,$59 ; 60,58 ; 61,66 ; 25,17$ e 48,57 , para a glicose, dextrina, amido de milho, milho triturado e pectina, respectivamente. A glicose apresentou o maior CDAEB e o milho, o menor.

TERMOS PARA INDEXAÇÃO: Jacaré-do-pantanal, caiman, digestibilidade, alimento, nutrição.

\section{APPARENT DIGESTIBILITY COEFFICIENTS OF FIVE ENERGETIC FOOD SOURCES FOR THE "JACARÉ-DO-PANTANAL" (Caiman yacare, Daudin, 1802)}

\begin{abstract}
A metabolism trial was carried out at the facilities of the Cooperative of growers of the "Jacaré do Pantanal" , in Cáceres - MT, with the objective of evaluating the nutritional value of five energetic feedstuffs for the "jacaré-do-pantanal" (Caiman yacare). A completely randomized design with five treatments and three replicates was utilized, the experimental unit being constituted of three caimans, with a total mean weight of $3940 \pm$ $240 \mathrm{~g}$, average environmental temperature of 30.5 $\pm 5.0^{\circ} \mathrm{C}$ and average temperature of the water of $27.8 \pm 1.0^{\circ} \mathrm{C}$. The amount of feed furnished per
\end{abstract}

replicate every two days was standardized in $20 \mathrm{~g}$ of dry matter per unit of metabolic weight $\left(\mathrm{kg}^{0.75}\right)$. The means of the coefficients of apparent digestibility were compared through Tukey's test $(\mathrm{P}<0,05)$. The coefficient of apparent digestibility of dry matter was of $80.78 ; 68.08 ; 69.91 ; 30.12$ and 58.95 and the coefficient of apparent digestibility of gross energy (CADGE) was of $82.59 ; 60.58 ; 61.66 ; 25.17$ and 48.57 for glucose, dextrin, cornstarch, ground corn and pectin, respectively. Glucose showed the highest CADGE value and corn the lowest $(\mathrm{P}<0,05)$.

\footnotetext{
1. Parte da dissertação de mestrado apresentada pelo primeiro autor ao Departamento de Zootecnia da UNIVERSIDADE FEDERAL DE LAVRAS/UFLA, Caixa Postal 37 - 37200-000 - Lavras, MG.

2. Professores da Escola Agrotécnica Federal de Cáceres/EAFC - MSc.

3. Professores do Deparatamento de Zootecnia da UFLA - DsC.
} 


\section{INTRODUÇÃO}

A criação do jacaré-do-pantanal em cativeiro (IBAMA, Portaria $\mathrm{n}^{\circ} .126$, de 13/02/90) tem como justificativa o melhor aproveitamento da pele, a diminuição da pressão sobre os estoques nativos e, assim, como outros animais silvestres, o sucesso da criação em cativeiro é um dos requisitos para evitar a extinção. É uma atividade recente, com poucas informações referentes ao sistema de criação, nutrição, instalações, processamento da pele, entre outros. A alimentação é o item que mais aumenta o custo de produção, e as rações utilizadas consistem em vísceras moídas de bovinos (pulmão e baço), misturadas com premix minerais e vitamínicos, normalmente recomendadas para suínos. A utilização de alimentos alternativos, que ajudariam a diminuir o custo com a alimentação, fica prejudicada em razão do desconhecimento do valor nutricional desses alimentos para os jacarés.

O jacaré-do-pantanal (Caiman yacare, Daudin, 1802) tem seu habitat natural na Bacia do rio Paraguai, é essencialmente carnívoro, atinge em cativeiro $2,5 \mathrm{~kg}$ aos 24 meses (Marques \& Monteiro, 1995), crescem mais rápido em temperaturas entre 25 e $32^{\circ} \mathrm{C}$ (Pinheiro et al., 1992), a taxa de passagem é de 5 dias a $30^{\circ} \mathrm{C}$ e 14 dias a $15^{\circ} \mathrm{C}$ (Diefenbach, 1975) e a digestibilidade aparente da proteína gordura e energia não é afetada na faixa de temperatura de 28 a $32^{\circ} \mathrm{C}$ (Staton et al., 1992).

Em vários trabalhos tem-se tentado demonstrar a capacidade de os crocodilianos digerirem alimentos de origem vegetal, visto que na natureza a ingestão desses alimentos resume-se em glicogênio ou glicose livre. Coulson (1976) determinou a digestibilidade da glicose, maltose, lactose, sacarose e amido (de milho, arroz, trigo e batata), concluindo que a glicose foi o único sacarídeo eficientemente digerido.

A glicose é lentamente absorvida em espécies carnívoras e insetívoras, em relação às espécies onívoras (Diamond, 1991). O jacaré-americano (Coulson \& Hernandez, 1983) e a truta arco-íris (Palmer \& Ryman, 1972) apresentam uma curva prolongada de tolerância à glicose em relação aos onívoros, indicando serem intolerantes à glicose. Porém, existem várias evidências de que a presença de carboidratos em pequena porcentagem na alimentação de carnívoros melhora a eficiência da utilização da proteína. Pieper \& Pfeffer (1980), em ensaios com truta arco-íris (Salmo gairdneri, R.), concluíram que o uso de sacarose ou amido gelatinizado de milho pode substituir parte da proteína que seria utilizada como fonte de energia, e Bergot (1979), em ensai- os com a mesma espécie, concluiu que pode ser utilizado níveis superiores a $30 \%$ de glicose na alimentação. Staton et al. (1990a) concluíram que a suplementação de aligatores com $20 \%$ de milho não afetou o desempenho, mas a utilização da mesma quantidade de glicose levou a um ganho significativamente melhor.

Os trabalhos sobre requerimentos nutricionais de crocodilianos são poucos, e normalmente determinados sobre uma única espécie. Melo (1991) recomenda um nível de proteína bruta (PB) de $47 \%$, e Staton et al. (1990b) recomendam uma concentração de energia bruta (EB) de 5180 a $5244 \mathrm{kcal} / \mathrm{kg}$ e uma relação EB:PB de 9,7 a 12,9:1 kcal/g de proteína, para um máximo desempenho do aligátor. A relação na dieta entre cálcio e fósforo recomendada para o aligátor é de 2:1 (Staton et al., 1991).

Com o presente trabalho objetivou-se determinar para o jacaré-do-pantanal o coeficiente de digestibilidade aparente da matéria seca e da energia dos seguintes alimentos: glicose, dextrina, amido de milho, milho e pectina.

\section{MATERIAL E MÉTODOS}

Foi conduzido um ensaio de digestibilidade nas instalações da Cooperativa de Criadores de Jacaré-doPantanal (Coocrijapan), localizada na cidade de Cáceres, Estado de Mato Grosso, no Pantanal Norte, tendo como coordenadas geográficas $16^{\circ} 13$ ' 42 " de Latitude Sul e 57 40' $51^{\prime}$ " de Longitude Oeste de Greenwitch, altitude de $118 \mathrm{~m}$, com temperatura anual média $25,2^{\circ} \mathrm{C}$, umidade relativa do ar média de $80,4 \%$ e precipitação pluviométrica anual média de $1.348 \mathrm{~mm}$ (Brasil, 1992). Foram formuladas seis rações, sendo uma basal (referência) e cinco experimentais, confeccionadas pela substituição de $30 \%$ (peso seco) da basal por um dos alimentos testados (glicose, dextrina, amido de milho, milho ou pectina).

A ração basal foi confeccionada inicialmente pela passagem do pulmão e baço pelo moedor de carne com disco de saída de $12 \mathrm{~mm}$, e posteriormente pela mistura dos demais ingredientes em misturador de carne utilizado para embutidos,. A partir da ração basal foram confeccionadas as rações experimentais, que foram embutidas em tripas de suínos (Clavijo et al., 1994), amarradas a cada $7 \mathrm{~cm}$ (formando uma "salsichinha" de aproximadamente $25 \mathrm{~g}$ ), acondicionadas em sacos plástico em quantidades suficientes para um dia de arraçoamento e armazenadas em freezer.

A composição nutricional da ração basal foi definida tomando-se como referência as rações normal-

Ciênc. agrotec., Lavras. V.27, n.3, p.675-680, maio/jun., 2003 
mente utilizadas pelos criadores (Aleixo, 2000), e a digestibilidade foi determinada pelo método indireto, utilizando $0,5 \%$ de óxido crômico como indicador. A composição nutricional dos alimentos testados encontra-se na Tabela 1, e a centesimal e nutricional da ração referência, na Tabela 2 .

TABELA 1 - Composição nutricional dos alimentos utilizados com base na matéria natural.

\begin{tabular}{lccc}
\hline \multicolumn{1}{c}{ Alimento } & MS (\%) & PB $(\%)^{\mathbf{2}}$ & $\begin{array}{c}\mathbf{E B} \\
(\mathbf{k c a l} / \mathbf{k g})^{\mathbf{2}}\end{array}$ \\
\hline Glicose & 97,54 & 0,30 & 3920 \\
Dextrina & 98,42 & 0,72 & 4013 \\
Amido de Milho & 89,63 & 0,68 & 3652 \\
Milho Moído & 87,62 & 8,76 & 3969 \\
Pectina & 88,33 & $1,30^{3}$ & 3171 \\
\hline
\end{tabular}

1/Análises realizadas no Laboratório de Solos EAFC-MT.

Análises realizadas no Laboratório de Nutrição Animal - UFLA.

3/ Porcentagem de nitrogênio

Cinqüenta e quatro jacarés de peso semelhante foram aleatoriamente distribuídos em 18 tanques de alvenaria, localizados em galpão fechado, com $2,0 \times 2,0 \times 0,6 \mathrm{~m}$ (comprimento, largura e altura), com o piso apresentando um desnível em forma de rampa no terço final, que na parte mais profunda fica com água a uma altura de aproximadamente 20 $\mathrm{cm}$. Três dos 18 tanques foram utilizados para a determinação do coeficiente de digestibilidade aparente da ração basal. O peso total médio dos jacarés de cada tanque foi de $3940 \pm 240 \mathrm{~g}$; a temperatura ambiente média, $30,5 \pm 5,0^{\circ} \mathrm{C}$, e a temperatura média da água, $27,8 \pm 1,0^{\circ} \mathrm{C}$.

$\mathrm{O}$ ensaio foi conduzido no mês de fevereiro de 2001, consistindo de um período de 14 dias de adaptação e um de 10, de coleta. As rações foram fornecidas uma vez a cada dois dias (Aleixo, 2000), em torno das 12 horas, à vontade, durante o período de adaptação, e controladas no período de coleta em $20 \mathrm{~g}$ de matéria seca para cada unidade de peso metabólico $\left(\mathrm{kg}^{0,75}\right)$, conforme o menor consumo verificado na fase de adaptação.
TABELA 2 - Composição centesimal e nutricional da ração referência com base na matéria seca (MS) e na matéria natural $(\mathrm{MN})$.

\begin{tabular}{lcc}
\hline \multicolumn{1}{c}{ Ingrediente } & \% na MS & \% na MN \\
\hline Pulmão bovino & 70,07 & 78,34 \\
Baço bovino & 15,27 & 17,86 \\
Fosfato Bicálcico & 1,58 & 0,40 \\
Calcário & 1,76 & 0,45 \\
Óleo de soja & 6,22 & 1,60 \\
Premix mineral/vit. ${ }^{1}$ & 4,60 & 1,22 \\
Óxido crômico $(\mathrm{Química}$ & 0,50 & 0,13 \\
Sulfal Ltda) & 100,00 & 100,00 \\
\hline TOTAL & 100,00 & 25,20 \\
\hline Matéria Seca $(\%)^{2}$ & 68,69 & 17,31 \\
Proteína Bruta $(\%)^{3}$ & 5416 & 1365 \\
\hline Energia Bruta $(\mathrm{kcal} / \mathrm{kg})^{3}$ & & \\
\hline
\end{tabular}

1/Premix mineral/vitamínico, níveis de garantia por Kg: Manganês $=890 \mathrm{mg}$; Zinco $=1.390 \mathrm{mg}$; Cobre $=$ $3.120 \mathrm{mg}$; Iodo $=18 \mathrm{mg}$; Selênio $=6 \mathrm{mg}$; Sódio $=30 \mathrm{~g}$; Cálcio = 180g; Fósforo = 36g; Vit. A = 58.300UI; Vit. D3 = 11.000UI; Vit. E = 175UI; Vit. B12 = 300 $\mu$ g; Niacina $=390 \mathrm{mg}$; Riboflavina $=50 \mathrm{mg}$; Ácido Pantotênico $=200 \mathrm{mg}$; Antioxidante $=200 \mathrm{mg}$; Flúor $=$ máximo 360mg; Solubilidade do fósforo em ácido cítrico a $2 \%=$ mínimo $90 \%$.

2/ Análises realizadas no Laboratório de Solos EAFC-MT.

3/ Análise realizada no Laboratório de Nutrição Animal - UFLA

Foi retirada uma amostra de cada ração na hora da alimentação, e durante o período de coleta, as fezes foram coletadas sempre que presentes, de manhã ou à tarde, sendo então armazenadas em freezer a $-10^{\circ} \mathrm{C}$. Ao final do período experimental, foram tomadas amostras representativa da ração e das fezes e secas em estufa com ventilação forçada a $65^{\circ} \mathrm{C}$. No Laboratório de Nutrição Animal do Departamento de Zootecnia da UFLA, as amostras foram analisadas para a determinação do teor de matéria seca(MS), por desidratação em estufa a $105^{\circ} \mathrm{C}$; energia bruta (EB), por combustão em

Ciênc. agrotec., Lavras. V.27, n.3, p.675-680, maio/jun., 2003 
bomba calorimétrica; e óxido crômico, por espectrofotometria de absorção atômica, segundo a metodologia descrita por Silva (1998).

Para o cálculo dos CDAs dos parâmetros avaliados, foi utilizada a seguinte fórmula:

$$
\mathrm{CDA}=100-100 \times \frac{(\% \text { indicador ração } \times \% \text { nutriente fezes })}{(\% \text { indicador fezes } \times \% \text { nutriente ração })}
$$

Os CDAs dos alimentos foram determinados pela diferença proporcional dos valores de digestibilidade da ração experimental em relação aos da ração referência, pela seguinte fórmula apresentada por Sugiura et al. (1998):

$$
\text { CDAat }=\frac{\text { CDAre } \times \text { Nre }-(1-S) \times \text { CDArr } \times \text { Nrr. }}{S \times \text { Nat }}
$$

em que o CDAat é o coeficiente de digestibilidade aparente do nutriente do alimento-teste; CDAre, o coeficiente de digestibilidade aparente do nutriente da ração experimental; CDArr, o coeficiente de digestibilidade aparente do nutriente da ração referência; Nre, porcentagem do nutriente ou concentração da energia na ração experimental; Nrr, porcentagem do nutriente ou concentração da energia na ração referência; Nat, porcentagem do nutriente ou concentração da energia no alimento-teste; S, fração da ração experimental que é constituída pelo alimento-teste.

Para a análise estatística dos coeficientes de digestibilidade, utilizou-se o seguinte modelo: $y_{i j}=\mu+t_{i}$ $+\mathrm{e}_{\mathrm{ij}}$, em que $\mathrm{y}_{\mathrm{ij}}$ é o coeficiente de digestibilidade aparente da matéria seca ou energia dos alimentos estudados; $\mu$, a média geral, $t_{i}$, o efeito do alimento, sendo $i=$ glicose, dextrina, amido de milho, milho moído ou pectina; $\mathrm{e}_{\mathrm{ij}}$, o erro experimental, e as médias foram comparadas pelo teste de Tukey $(\mathrm{P}<0,05)$.

\section{RESULTADOS E DISCUSSÃO}

O desempenho zootécnico dos jacarés, expresso pelo ganho de peso diário e pela conversão alimentar, determinados durante os 24 dias do experimento, está representado na Tabela 3 .

O ganho de peso diário e a conversão alimentar verificados durante os 24 dias de experimento mostram que os alimentos utilizados na composição da ração não possuem efeitos negativos sobre o desempenho, e que as rações embutidas em tripa de suíno foram bem aceitas, mascarando possivelmente qualquer efeito da palatabilidade desses alimentos.
TABELA 3 - Média e respectivo desvio-padrão do ganho de peso diário (GPD) e conversão alimentar (CA) verificados durante os 24 dias de experimento em cada unidade experimental composta de três jacarés (Caiman yacare).

\begin{tabular}{lll}
\hline \multicolumn{1}{c}{ Ração } & GPD $(\mathbf{g})$ & CA \\
\hline Referência & $26,3^{(5,6)}$ & $1,12^{(0,12)}$ \\
Referência + Glicose & $40,2^{(8,5)}$ & $0,83^{(0,15)}$ \\
Referência + Dextrina & $37,1^{(1,31)}$ & $0,91^{(0,02)}$ \\
Referência + Amido & $35,5^{(6,4)}$ & $0,96^{(0,20)}$ \\
Referência + Milho & $32,3^{(4,3)}$ & $0,99^{(0,08)}$ \\
Referência + Pectina & $11,9^{(4,1)}$ & $2,51^{(0,87)}$ \\
\hline
\end{tabular}

Os resultados referentes aos coeficientes de digestibilidade aparente da matéria seca e energia bruta encontram-se na tabela 4, e o nível de energia digestível, gerado a partir da multiplicação do coeficiente de digestibilidade da energia bruta pelo teor de energia bruta, encontra-se na Tabela 5 .

TABELA 4 - Valor médio e respectivo desvio-padrão dos coeficientes de digestibilidade aparente da matéria seca (CDAMS) e energia bruta (CDAEB) dos alimentos testados.

\begin{tabular}{lcc}
\hline \multicolumn{1}{c}{ Alimento } & CDAMS & CDAEB \\
\hline Glicose & $80,78^{(1,80)} \mathrm{a}$ & $82,59^{(2,38)} \mathrm{a}$ \\
Dextrina & $68,08^{(1,80)} \mathrm{b}$ & $60,58^{(2,23)} \mathrm{b}$ \\
Amido milho & $69,91^{(1,97)} \mathrm{b}$ & $61,66^{(3,31)} \mathrm{b}$ \\
Milho & $30,12^{(5,87)} \mathrm{d}$ & $25,17^{(7,33)} \mathrm{d}$ \\
Pectina & $58,95^{(2,27)} \mathrm{c}$ & $48,57^{(3,91)} \mathrm{c}$ \\
\hline CV $(\%)^{2}$ & 5,13 & 7,64 \\
\hline
\end{tabular}

1/ Colunas com médias seguidas de mesma letra não diferem estatisticamente entre si pelo teste de Tukey (P > 0,05).

${ }^{2} /$ Coeficiente de Variação. 
TABELA 5 - Valor médio e respectivo desvio-padrão da energia digestível (ED), dos alimentos energéticos, expressos com base na matéria natural.

\begin{tabular}{lcc}
\hline \multicolumn{1}{c}{ Alimento } & MS $(\%)$ & ED (kcal/kg) \\
\hline Glicose & 97,54 & $3238^{(93)}$ \\
Dextrina & 98,42 & $2431^{(89)}$ \\
Amido de Milho & 89,63 & $2252^{(121)}$ \\
Milho & 87,62 & $999^{(291)}$ \\
Pectina & 88,33 & $1540^{(124)}$ \\
\hline / Gerados a partir & dos CDAs determinados neste \\
experimento. &
\end{tabular}

Houve diferença significativa $(\mathrm{P}<0,05)$ entre as médias dos CDAEB, e a glicose apresentou o maior $(82,59)$ e o milho, o menor $(25,17)$. O menor CDAEB do milho determinado com o jacaré gerou uma energia digestível de $999 \mathrm{kcal} / \mathrm{kg}$, que está próximo do valor de energia digestível determinado para trutas, que é de $1100 \mathrm{kcal} / \mathrm{kg}$ (NRC, 1993), indicando que o jacaré, como os peixes carnívoros, tem limitações em aproveitar esse alimento. Mesmo assim, o CDAEB do milho é baixo quando comparado com o do amido $(61,66)$, podendo ter tido interferência da granulometria, já que o milho utilizado foi grosseiramente triturado (peneira com furo de saída de $9,5 \mathrm{~mm}$ ).

A pectina utilizada foi a de baixo metoxil amidada, que tem a propriedade de formar gel tanto a quente quanto a frio em uma larga faixa de sólidos solúveis $(10$ a $80 \%)$ e $\mathrm{pH}(2,6$ a 6,0$)$, apresentou um baixo CDAEB $(48,57 \%)$ estatisticamente $(\mathrm{P}<0,05)$ menor que a dextrina e o amido, o que é justificado pela incapacidade dos monogástricos de digeri-la enzimaticamente, estando sua digestibilidade sujeita à habilidade dos microorganismos em quebrar os polissacarideos e fermentar os monossacarídeos resultantes dessa quebra, o que deve ocorrer em pequena escala, visto que o jacaré possui um intestino grosso muito curto. No intestino delgado, a pectina promove a redução da absorção de vários nutrientes, mediante a formação de géis que prejudicam a atividade enzimática, redução no esvaziamento gástrico, impacto sobre a difusão e absorção dos nutrientes ou aumento da viscosidade da digesta (Johansen et al., 1996). Apesar da alta viscosidade, a pectina não foi rejeitada pelos jacarés, e o seu uso, nesse caso, se justificaria como agregante em rações secas, que seriam umedecidas no momento do fornecimento, aproveitando as propriedades geleificantes.

O CDAEB da dextrina comparou-se com o do amido, porém, ficou bem abaixo do encontrado por Staton et al. (1992), que foi de 93,1\% quando a dextrina substituiu $16 \%$ da energia da ração.

O baixo coeficiente de digestibilidade dos carboidratos determinado para o jacaré em relação aos onívoros (segundo Rostagno et al., 2000, o coeficiente de digestibilidade da energia determinado com suínos da glicose, amido e dextrina, fica acima de 90\%) indica uma menor capacidade da utilização desses alimentos, o que já foi relatado por Coulson \& Hernandez (1983) para o aligátor.

\section{CONCLUSÕES}

O coeficiente de digestibilidade aparente da matéria seca foi de 80,$78 ; 68,08 ; 69,91 ; 30,12$ e 58,95; e o coeficiente de digestibilidade aparente da energia bruta foi de 82,$59 ; 60,58 ; 61,66 ; 25,17$ e 48,57 para a glicose, dextrina, amido de milho, milho moído e pectina, respectivamente.

\section{REFERÊNCIAS BIBLIOGRÁFICAS}

ALEIXO, V. M. Efeitos do uso de farelo de soja e de sistemas de alimentação sobre o desempenho de filhotes de jacaré-do-pantanal Caiman yacare (DAUDIN, 1802). 2000. 92 p. Dissertação (Mestrado em Zootecnia) - Universidade Federal de Lavras, Lavras.

BERGOT, F. Carbohydrate in rainbow trout diets effects or the level and source of carbohydrate and the number of meals on growth and body composition. Aquaculture, Amsterdam, v. 18, p. 157-67, 1979.

BRASIL. Ministério da Agricultura. Normais climatológicas 1961-1990. Brasília, 1992. 84 p.

ClAVIJO, L. A.; LOPES, O.; GERARDINO, A. G.; RODRIGUES, M. Evaluacion de materias primas animales y vegetales y de enzimas en concentrados para neonatos de Caiman crocodilus fuscus. Revista ICA, Salle, v. 29, p. 239-248, 1994.

COULSON, R. A.; HERNANDEZ, T. Alligator metabolism, studies of chemical reactions "in-vivo". New York: Pergamon, 1983. 
COULSON, R. A. Qualitative requirements and utilization of nutrients: reptiles. In: Handbook of nutrition. Cleveland: Rubber Company, 1976.

DIAMOND, J. M. Evolutionary design of intestinal nutrient absortion: enough but not too much. News Phisiology Science, [S.1.], v. 6, p. 92-96, 1991.

DIEFENBACH, C. O. Gastric function in Caiman crocodilus Rates of gastric digestion and gastric mobility as a function of temperature. Comparative Biochemistry and Physiology, London, v. 51A, p. 259-265, 1975.

JOHANSEN, H.; KNUDSEN, K. E. B.; SANDSTRÖN, B.; SKIJOTH, F. Effectsof varying content of soluble dietary fibre from wheat flour and oat milling fractions on gastric emptying in pigs. The British Journal of Nutrition, New York, v. 75, n. 3, p. 339-351, 1996.

MARQUES, E. J.; MONTEIRO, E. L. Ranching de Caiman crocodilus yacare no Pantanal de Mato Grosso do sul, Brasil. In: LARRIERA, A.; VERDADE, L. M. La conservacion y el manejo de caimanes e crocodrilos de América Latina. Santa Fé: Fundacion Banco Bica, 1995. v. 1, p. 189-211.

MELO, B. Estudos monograficos sobre Caiman crocodilus fuscus como especie para zoocria y avaliacion del crescimiento de juveniles, bajo tres regimenes alimenticios en la Granja Monterrey Florestal Zambrano. Caldas: Faculdad de Medicina Veterinária e Zootecnia Unia Caldas, 1991. 168 p.

NATIONAL RESEARCH COUNCIL. Nutrient requirements of fish. Washington: National Academy, 1993. $115 \mathrm{p}$.

PALMER, T. N.; RYMAN, B. E. Studies on oral glucose tolerance in fish. Journal of Fish Biology, New York, v. 4, p. 311-319, 1972.

PIEPER, A.; PFEFFER, E. Studies on the effect of increasing proportions of sucrose or gelatinized maize starch in diets for rainbow trout (Salmo gairdneri, R.) on the utilization of dietary energy and protein. Aquaculture, Amsterdam, v. 20, p. 333-342, 1980 .
PINHEIRO, M. S.; SANTOS, S. A.; SILVA, R. A. Efeito da temperatura da água sobre o crescimento inicial de Caiman crocodilus yacare. Revista Brasileira de Biologia, Rio de Janeiro, v. 52, n. 1, p. 161-168, 1992.

ROSTAGNO, H. S.; ALBINO, L. F. T.; DONZELE, J. L.; GOMES, P. C.; FERREIRA, A. S.; OLIVEIRA, R. F.; LOPES, D. C. Composição de alimentos e exigências nutricionais de aves e suínos: tabelas brasileiras. Viçosa: UFV, 2000. $141 \mathrm{p}$.

SILVA, D. J. Análises de alimentos: métodos químicos e biológicos. Viçosa: UFV, 1998. 116 p.

STATON, M. A.; BRISBIN, I. L.; PESTI, G. M. Formulación de alimentos para lagartos: antecedentes y estudios iniciales. In: KING, F. W. (Ed.). Crianza de cocodrilos: informaciones de la literatura científica. Gland: IUCN, 1991. p. 117-134.

STATON, M. A.; EDWARD, H. M.; BRISBIN, I. L.; JOANEN, T.; McNEASE, L. Dietary energy sources for the American alligator, Alligator mississippiensis. Aquaculture, Amsterdam, v. 89, p. 245261, 1990a.

STATON, M. A.; EDWARD, H. M.; BRISBIN, I. L.; JOANEN, T. Protein and energy relationships in the diet of the American alligator Alligator mississippiensis. Journal of Nutrition, Bethesda, v. 120, n. 7, p. 775-785, 1990b.

STATON, M. A.; EDWARD, H. M.; BRISBIN, I. L.; JOANEN, T.; McNEASE, L. The influence of environmental temperature and dietary factors on utilization of dietary energy and protein in purified diets by Alligators (Aligator mississippiensis). Aquaculture, Amsterdam, v. 107, p. 369-381, 1992.

SUGIURA, S. H.; DONG, F. M.; RATHBONE, C. K.; HARDY, R. W. Apparent protein digestibility and mineral availabilities in various feed ingredients for salmonid feeds. Aquaculture, Amsterdam, v. 159, p. 177-202, 1998. 